\title{
STUDI HUKUM ISLAM TERHADAP KONTRAK PERJANJIAN BANKING CARDS
}

\author{
Ari Kartini ${ }^{1}$, Ifayani Hanurat ${ }^{2}$ \\ ${ }^{1}$ Mahasiswa Prodi Hukum Ekonomi Syariah FAI Unismuh Makassar \\ ${ }^{1}$ Dosen Prodi Hukum Ekonomi Syariah FAI Unismuh Makassar
}

Abstrak

Penelitian Ini Bertujuan Untuk Mengetahui Bagaimana Studi Hukum Islam Terhadap Kontrak Perjanjian Banking card (Kasua Hasanah card Bank BNI Syariah) dengan mengetahui pelaksanaan akad sesuai dengan prinsip syariah, bagimana bentuk/mekanisme kontrak perjanjian, bagaimana persepsi nasabah terhadap hasanah card.

Jenis Penelitian Yang Digunakan Penulis Adalah Kualitatif. Kualitatif yaitu menjelaskan dan menguraikan data-data yang telah dikumpulkan, Metode pengumpulan data dengan wawancara, observasi, dan dokumentasi. Wawancara di lakukan pada marketing banking card khusus hasanah card, coustumer sevics, dan nasabah bank BNI Syariah cabang Makassar. Untuk menguji Keabsahan data dengan menggunakan teknik uji trianggulasi.

Hasil penelitian menunjukkan bahwa kartu kredit hasanah card BNI syariah hukumnya boleh, karena dalam akad hasanah card sudah memenuhi rukun dan syarat terjadinya akad dalam Islam serta sesuai dengan prinsip syariah. Kontrak perjanjian hasanah card ada beberapa tahapan antara lain Al-Ariyah (perjanjian kredit), Al-Wakalah (perjanjian pemberian kuasa), dan Al-Kafalah (perjanjian penanggungan). Persepsi nasabah terhadapa banking card dilihat dari berbagai sisi dari pengetahuan nasabah kurang mengetahui akad-akad yang di gunakan dalam hasanah card, dari sisi Diskon dan promo kurang hal ini mengakibatkan minat nasabah terhadap produk ini tidak mengalami kenaikan signifikan, akan tetapi tidak mengurangi kenyamanan dan tingkat harga pricing yang di miliki bank BNI Syariah masih tetap kompetitif sekalipun diskon ada atau kurang, kemudian untuk pelayanan terhadap nasabah sangat baik dan tidak ada komplain nasabah terhadap fasilitas yang ada di bank BNI syariah.

Kata kunci: hukum islam, kotrak perjanjian(akad), hasanah card.

\begin{abstract}
This Research Aims To Know How Islamic Law Studies Against Contract Banking Card Agreement (Kasua Hasanah Card Bank BNI Syariah) by knowing the implementation of the contract in accordance with the principles of sharia, how the form / contract agreement mechanism, how the customer's perception of hasanah card.

Type of Research Used The author is Qualitative. Qualitative is to explain and describe the data that has been collected, Methods of data collection with interviews, observation, and documentation. Interviews conducted on marketing banking card special hasanah card, coustumer sevics, and bank customers BNI Syariah Makassar branch. To test the validity of data by using triangulation test technique.
\end{abstract}

The results showed that hasanah card credit card BNI syariah law allowed, because in akad hasanah card already meet the pillars and terms of the contract in Islam and in accordance with the principles of sharia. Hasanah card agreement contract there are several stages, among others Al-Ariyah (credit 
agreement), Al-Wakalah (power of attorney agreement), and Al-Kafalah (contractual arrangements). The perception of the customer to the banking card is seen from various facets of the knowledge of the customers are less aware of the contracts that are used in hasanah card, in terms of discounts and promos less this resulted in customer interest in this product did not increase significantly, but did not reduce the comfort and level the pricing price of BNI Syariah bank is still competitive even if the discount is present or less, then for the service to the customer is very good and no customer complaints against the existing facilities in the bank BNI sharia.

Keywords: Islamic law, contract agreement (akad), hasanah card.

\section{A. PENDAHULUAN}

Perbankan Syariah membawa warna baru bagi dunia perbankan di Indonesia disamping

konvensional yang telah ada sebelumnya. Indonesia merupakan Negara mayoritas penduduk islam, sehingga tidak heran jika sistem yang digunakan diberbagai aspek tidak jauh dari unsur islam, salah satunya dalam Sistem Ekonomi. Sejak tahun 1992 di Indonesia mulai muncul bank yang mengunakan Prinsip Syariah yaitu Bank Muamalah Indonesia(BMI) yang merupakan hasil lokakarya yang diadakan oleh MUI, pada tahun 1998 ketika Indonesia mengangalami krisis moneter. Kepercayaan masyarakat terhadap Bank Syariah mulai meningkat.

Bank BNI Syariah yang bekerja sama dengan MasterCard menerbitkan Hasanah cardyang merupakan kartu kredit yang berprinsip syariah pada tangal 7 Februari 2009 dan yang mempelopori pertama munculnya kartu kredit Syariah adalah Bank Danamon Syariah dengan nama Dirham Card, ini muncul pada tanggal 19 Juli 2007.

Kartu kredit atau credit card merupakan gaya hidup dan bagian dari komunitas manusia untuk dapat dikatakan moderen dalam tata kehidupan sebuah kota yang beranjak menuju kota metropolitan atau cosmopolitan. (Ibrahim, 2004: 7). Di sisi lain, masyarakat masih beraganggapan bahwa kartu kredit syariah(hasanah card) sama dengan kartu kredit konvensional dan menganggap bahwa produk syariah juga menggunakan sistem bunga berbunga seperti halnya bank konvensional.

Penggunaan kartu kredit syariah bank syariah tidak mendorong nasabahnya untuk berlebihan dalam menggunakan kartu kredit syariah sebagaimana firman Allah dalam QS. al-Furqan: 67: 


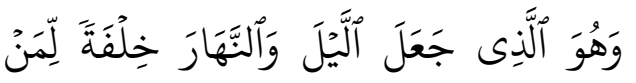

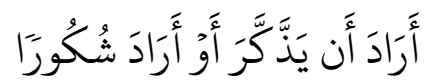

Terjemahannya:

Dan orang-orang yang apabila membelanjakan (harta), mereka tidak berlebih-lebihan, dan tidak (pula) kikir, dan adalah (pembelanjaan itu) di tengah-tengah antara yang demikian.

Ditinjau dari aspek hukum, hasanah card di payungi oleh fatwa DSN-MUI nomor 54/DSN-MUI/IX/2006. Sebagaimana dalam situs resmi BNI Syariah menyebutkan produk ini terdiri dari tiga akad,:kafalah , qardh, dan ijarah. Akad adalah suatu perikatan antara ijab dan qabul dengan cara yang dibenarkan syara' yang menetapkan adanya akibat- akibat hukum objeknya. (Basyir,2004: 65)

Hukum Islam sebagai hukum yang berdasarkan nilai-nilai yang terkandung dalam Islam. Sehubungan dengan hal tersebut maka (Ali,1996:39) hukum Islam menjelaskan sebagai berikut:

Hukum Islam adalah seperangkat tingkah laku yang mengatur tentang hubungan seorang manusia dengan Tuhan, sesama manusia dan alam sekitarnya yang berasal dari Allahta'ala• .

Selanjutnya juga Hasbi AshShidieqy memberikan pengertian hukum Islam sebagai berikut:

Hukum Islam adalah hukum yang bersifat umum dan kulli yang dapat diterapkan dalam perkembangan hukum Islam menurut kondisi dan situasi masyarakat dan masa.

Kontrak adalah undang-undang yang mengawal urusan perjanjian. Perjanjian adalah suatu persetujuan di antara dua pihak atau lebih berkenaan sesuatu perkara. Perlulah difahami bahwa istilah kontrak adalah lebih khusus manakala istilah perjanjian adalah lebih umum. Hanya perjanjian yang mempunyai ciri-ciri kontrak saja yang mempunyai implikasi undangundang.

Perbedaan antara Perjanjian Islam (Akad) dengan Perjanjian KUH Perdata adalah dalam tahapan perjanjiannya dimana dalam hukum Perjanjian Islam (Akad) janji Pihak Pertama dan Pihak Kedua terpisah atau dua tahap sedangkan dalam $\mathrm{KUH}$ Perdata hanya satu tahap setelah ada perjanjian maka timbul perikatan. Beberapa define yang diberikan kepada perjanjian:

1. Menurut pasal 262 Mursyid Al Hairan, akad merupakan, "Pertemuan ijab ynag dilakukan oleh salah satu pihak dengan kabl dari pihak lain tang enimbulkan akibat hukum pada objek akad" ( Mursyid Al Hairan,1403/1983:49) 
2. "Pertemuan ijab dan Kabul bersifat tetap, adil, transparan, dan sebagai pernyataan kehendak kompetitif tanpa perhitungan bunga.iB dua pihak atau lebih untuk hasanah card adalah kartu berbasis melahirkan suatu akibat hukum Syariah yang berfungsi seperti kartu pada objeknya" (Samsul,2007: pembiayaan sehingga diterima di 68) seluruh tempat bertanda MasterCard

Istilah umum yang dipakai untuk dan semua ATM yang bertanda inter exchange keuangan dalam CIRRUS di seluruh dunia.

bahasa inggris dan perundang-

IB hasanah card adalah salah undangan kadangkala dinamakan satu kartu kredit yang menggunakan dengan financial transactions cards, akad Syariah, yang diterbitkan oleh kadangkala dengan payment cards.

BNI Syariah,dengan ketentuan Fatwa

Adapun istilah yang dipakai oleh DSN-MUI tentang syariah card. ekonomi arab dengan bithaqah al- Hasanah card memiliki 3 jenis yaitu : l'timan pada hakikatnya merupakan Hasanah card Classic,Hasanah card bhitaqah al-iqradah, lebih baik dengan Gold, Dan Hasanah card Platinum. istilah tersebut karena gambaranya lebih fokus terhadap istilah financial transactions cards dalam bahasa inggris. Definisi BANKING CARDS sendiri adalah : "instrument -instrumen dengan nama bithaqah iqradah, atau kartu layanan perbankan atau BANKING CARDS, atau bithaqah cek madhmun, atau bithaqah sahib mubasir,atau istilah lain yang diterbitkan secara resmi ataupun tidak resmi oleh penerbitnya."(Ibrhim,2006:

Hasanah card pada produk bni syariah kartu pembiayaan yang berfungsi sebagai kartu kredit

\section{B. METODOLOGI PENELITIAN}

Jenis penelitian ini adalah Penelitian kualitatif, yaitu prosedur penelitian yang menghasilkan data deskriftif berupa kata-kata tertulis atau lisan dari orang-orang dan perilaku yang dapat diamati.

Sumber data dalam penelitian ini adalah individu yang di jadikan sasaran kasus yang di teliti sebagai sumber informasi.Sedangkan yang menjadi obyek penelitian ini yaitu tentang kontrak perjanjian banking card prinsip syariah. Penulis akan berusaha untuk berdasarkan prinsip syariah, yaitu meneliti tentang study hukum islam dengan sistem perhitungan biaya 
cards (kasus hasanah card Bank BNI syariah).

Desain penelitian adalah strategi dalam menyusun model penelitian agar diperoleh data-data maupun kesimpulan penelitian dengan kemunkinan munculnya penyimpangan yang paling kecil sekalipun dari variabel tertentu. Langkah-langkah penelitian: 1) Tahap persiapan Pengumpulan data di lapangan dilakukan dengan cara wawancara langsung. 3) Setelah semua bahan yang dibutuhkan terkumpul, maka disusunlah kedalam bentuk skripsi sesuai dengan metode yang telah ditentukan.

Dalam penelitian ini,penulis akan menggunakan dua metode pengumpulan data, yaitu: 1) Library Research (riset kepustakaan), yaitu dengan mengumpulkan data yang dilperoleh melalui study kepustakaan. 2) Field Research, yaitu mengumpulkan data melalui penelitian lapangan, dengan menggunakan metode sebagi berikut: (a) Wawancara (b) Metode Obseravasi (b) Metode Dokumentasi

Metode analisis data yang digunakan penelitian adalah analisis kualitatif, yaitu suatu metode yang menggambarkan sebuah fakta yang kemudian dianalisa sebuah kesimpulan dari data fakta dengan menggunakan analisa fenomenologi dimana Penelitian ini akan berdiskusi tentang suatu objek kajian dangan memahami inti pengalaman dari suatu fenomena.

Pengecekan keabsahan data. Peneliti melakukan pengecekan dengan menggunakan trianggulasi sumber agar data dalam penelitian ini valid dan dapat dipertanggung jawabkan.

\section{HASIL PENELITIAN DAN PEMBAHASAN}

Tinjauan Hukum Islam Akad Produk Hasanah card

Berdasarkan hasil wawancara dengan pihak manajemen BNI syariah cabang makassar, sebagaimana model wawancara yang dapat di peroleh dalam pelaksanaan akad produk hasanah card. Dalam hal ini hasil wawancara penulis dengan marketing pengelola kartu hasanah card ibu nur fauziah, diperoleh keterangan dan penganalisaan sebagaimana maksud penulisan.

Pada tahun 2006 DSN MUI mengeluarkan fatwa yang membolehkan adanya kartu kredit syariah, dengan Fatwa No.54/DSNMUI/X/2006 Dewan Syariah Nasional Majelis Ulama Indonesia (DSN MUI). 
Dan pada tahun 2007 Bl mengeluarkan regulasi tentang kartu kredit syariah yaitu Surat Bank Indonesia No.9/183/DPbS/2007. Mengenai hal tersebut juga dijelaskan oleh marketing hasanah card BNI Syariah cabang makassar bagian dari penerbit IB Hasanah card yang dilakukan melalui wawancaralbu Nur Fauziah marketing Hasanah card.adapun hasil wawancara beliau mengatakan:

"Alhamdulillah setiap produk yang di keluarkan oleh BNI Syariah di sesuaikan dengan fatwa MUI, contoh hasanah card dengan Fatwa No.54/DSN-MUI/X/2006"

Menurut penulis melihat dari beberapa penjelasan tentang kesesuaian prinsip syariah terhadap akad hasanah card bahwaakad yang di jalankan oleh bank BNI Syariah sesuai dengan syariah yang mengacu pada Fatwa No.54/DSN-MUI/X/2006 tentang syariah card.

Presentase yang dipotong oleh pihak Bank yang mengeluarkan kartu dari pengusaha. Peraturan Bank Indonesia No: 6/24/PBI/2004 tentang Bank Umum yang melaksanakan kegiatan berdasarkan prinsip syariah. Dalam pasal 36 huruf $\mathrm{m}$ menyatakan "Bank dapat melakukan kegiatan usaha kartu kredit, charge card berdasarkan prinsip syariah". Fatwa DSN No : 42/DSN-MUI/V/2004 yang menetapkan "Bahwa penggunaan charge card secara syariah diperbolehkan". (Dewi, Gemala. dkk. 2005:211). Untuk mengetahui benar tidaknya maka kami mewawancarai pihak marketing hasanah card dan informen lainya, beliau menyatakan :

"Kalau di bank syariah intinya kan denda itu fungsinya mendisiplinkan jadi semua bank ada jadi semua bank pasti ada denda, di bank BNI Syariah sendiri belum menerapkan denda.belum pernah.kalaupun nasabah terlambat bayar kita tidak pernah memberikan denda.kalau misalakan ada denda,kami tidak akui di pendapatan karena itu tidak boleh. Jadi denda nya kita masukan di dana zakat atau qordul hasan.

Berdasarkan hasil wawancara diatas penulis dapat menyimpulkan bahwa hasanah card pada bank BNI syariah tidak menggunakan sistem denda dan ta'wid di karenakan kehatihatian dan agar terhidar dari riba nasi'ah.

Berdasarkan fatwa DSN-MUI tentang syariah card, terhadap prinsip -prinsip syariah yang harus diterapkan dan ada pula yang harus di hindari,seperti riba, gharar, dan isyraf. Untuk menghindari praktek ini dari card syariah melakukan langkah sebagaimana wawancara kami kepada lbu Besse marketing hasanahcard 
mengenai limit hasanah card, beliau mengatakan:

"Kalau di lihat dari profile maka mungkin banyak nasabah yang mau limitnya lebih besar tapi kembali lagi kita lihat profil nasabah . tapi yang biasanaya di minati itu adalah classic dan gold.Akan tetapi kami dari pihak bank akan menyeleksi nasabah yang ingin membuat kartu hasanah card "Maksud kami dari pihak bank menyeleksi nasabah, kami melakukan demikian bukan kami bermaksud untuk membatasi nasabah yang ingin menggunakan produk kami, akan tetapi karena kami ingin memiliki nasabah yang bertanggung jawab dalam menyelesaikan pembayaran transaksi yang dilakukannya. dengan ketentuan dilihat dari penghasilan bulanan, kebutuhan bulanan, bagi yang telah menikah mencantumkan berapa jumlah anak"

Kemudian kami mewawancarai ibu Wina salah satu nasabah sendiri dan mengatakan bahwa:

"Yang classi .Yang limit 4 juta ,Pernah di tawari naik limit tapi saya gak mau. sesuai kebutuhan saya agar saya tidak konsumtif. "

Berdasarkan wawancara penelitian penulis, pagu maksimal ditentukan berdasarkan permohonan dari nasabah atas kebutuhannya masingmasing dan berdasarkan pendapatanya yang telah diperhitungkan oleh penerbit fasilitas. Pagu maksimal dimaksudkan untuk menahan nasabah dalam melakukan transaksi yang berlebihan. serta disesuaikan dengan jenis kartu yang di gunakan oleh nasabah. Dan jenis kartu di sesuaikan dengan penghasilan yang di peroleh nasabah setiap bulannya. hal ini di maksudkan agar tidak terjadi kredit macet.

\section{Kontrak Perjanjian Banking card Dalam Produk Hasanah card}

Sebagaimana hasil wawancara kami dengan ibu Nur Fauziah selaku marketing hasanah card :

"Disini ada yang namanya AlAriyah(perjanjian kredit), AlWakalah(perjanjian pemberian kuasa), dan Al-Kafalah(perjanjian penanggungan). Penjelasannya bisa di lihat di buku pedoman"

Kemudian kami mencoba mewawancarai ibu Lala salah satu nasabah mengenai syarat dalam perjanjian:

"Syarat begitu semua bank sama pakai seperti itu namun hanya sedikit berbeda. Kalau menurut saya ya harus di ikuti kita membutuhkan ingin bekearja samadengan bank tidak mungkin menggunakan aturan dari kita pasti kita harus mengikuti aturannya dia. "

Hasanah card terbagi menjadi beberapa kartu dengan kualifikasi penghasilan minimum tahunan yang berbeda dan disertai syarat-syarat, yaitu: 
Tabel:4.1

Kriteris pembiayaan syariah

\begin{tabular}{ccc}
$\begin{array}{c}\text { BNIHasanah } \\
\text { card }\end{array}$ & PenghasilanMinimumPemegang KartuUtama & $\begin{array}{c}\text { Pemegang } \\
\text { KartuTambahan }\end{array}$ \\
\hline Hasanah Gold & Rp.60 juta/thn & Usia min. 21 thn,maks. 65Usia min. 17 thn,maks.
\end{tabular}
thn 65 thn

Hasanah Classic Rp. 25 juta/thn Usia min. 21 thn,maks 65Usia min. 17 thn,maks thn 65 thn

Sumber: www.bnisyariah.co.id

Dokumen pendukung yang harus di lampirkan beserta formulir isian aplikasi hasanah card Sebagaimana hasil wawancara kami dengan ibu besse selaku coustumer sevice yaitu:

"Kalau ada nasabah yang ingin dan berminat dengan produk kami maka nasabah hanya mengisi aplikasi dan menyediakan KTP, dan lebih kita lihat profil nasabah ,slip gaji, dll kalau dia pengusaha maka kami butuh copy rekeningnya slip gaji”

\section{Persepsi Nasabah Terhadap \\ Banking card}

Persepsi masyarakat terhadap produk-produk bank syariah akan menimbulkan langkah yang akan di lakukan setelah hal itu terjadi. Pembentukan Persepsi yang baik di masyarakat akan memberikan dampak yang positif ,yang akan mempengaruhi masyarakat untuk memilih produk bank syariah. Khususnya hasanah card di bank BNI syariah cabang Makassar.
Sebagaimana hasil wawancara kami dengan ibu nur fauziah selaku marketing hasanah card :

"Kalau di Makassar sendiri sudah $40 \%$. kenapa? karena sebenarnya di sini daerahnya sangat potensial , akan tetapi banyak yang alergi terhadap kartu kredit, untuk menjual produk ini kita butuh usaha untuk menjelaskan ke nasabah tentang hal ini, menjelaskannya pun harus berhati hati karena ada sebagian orang yang mengaggap 'kenapa ada bank syariah yang mengunakan produk kartu kredit padahal di bank bni syariah mengunakan sistem syariah dan tidak mengunakan bunga'. Sistem yang di pakai bank syariah adalah setiap nasabah yang menguakan hasanah card untuk transaksi berapapun itu maka secara otomatis akan memberikan fee kepada bank,semakin banyak nasabah bertransaksi maka akan semakin sedikit Cash Rebate, hal ini di lakukan agar nasabah tidak boros dalam belanja , jadi sistemnya di tetapkan oleh nasabah sendiri. Bank syariah bisa di terima karena disisni mayoritas muslim tapi sampai sekarang masihberusaha merubah manshet masyarakat mengenai bank syariah .tantangannya disini kita 
menjual produk sambil
berdakwah."

Banyaknya produk perbankan syariah yang belum tersosialisasi kepada masyarakat luas sehingga peminat produk tersebut masih sangat minim. Pembentukan Persepsi akan memberikan dampak terhadap kemajuan bank syariah juga akan mendorong masyarakat untuk dapat menggunakan produk bank syariah. Persepsi dirasakan sangat penting, karena Persepsi adalah pengamatan tentang objek, peristiwa atau hubungan-hubungan yang diperoleh dengan menyimpulkan informasi dan menafsirkan pesan. Penelitian dilakukan dengan mewawancarai beberapa informan yang dalam hal ini adalah nasabah Bank BNI Syariah cabang Makassar. Dari hasil penelitian di lapangan, di peroleh data yang dapat memberikan informasi yang berkaitan dengan Persepsi - Persepsi nasabah terhadap produk hasanah card. Dari hasil observasi dan wawancara yang dilakukan kemudian peneliti melakukan analisis Persepsi nasabah terhadap produk hasanah card tersebut. Dari hasil wawancara yang dilakukan kepada 9 informan, penulis memperoleh beberapa Persepsi nasabah Bank BNI Syariah cabang Makassar. Diantaranya adalah bahwa 6 dari 9 nasabah yangkami wawancarai tidak mengerti secara pasti tentang akad produk hasanah card, hal ini diungkapkan oleh beberapa informan:

"lya saya tau sedikit ,saya Cuma pakai aja yah mba untuk sebut berapa akadnya saya lupa mba tapi salah satunya kafalah gitu, intinya saya di sini Cuma pakai aja, ya kalau ada promo saya pakai kalau tidak ya tdak saya paki begitu lah mba"(Nur Wayu Octavia)

"Akadnya itu ada Kafalah, ada Qard, Ada ljarah, itu punya fungsi masing masing tapi saya lupa pengertian selebihnya." (Muhammad Saleh/)

"Akad produk hasnah card saya tidak terlalu pahami detilnya"(Lala)

Sebagaimana wawancara kami dengan beberapa informan dan kebanyakan mereka menggunakan hasanah card tanpa tahu makna akadakad yang dipergunakan dalam operasional hasanah card.Nasabah yang tidak mengetahui secara pasti ini menganggap demikian karena memang keterbatasan mereka akan pengetahuan serta minimnya edukasi yang mereka dapatkan dari praktisi perbankan maupun dari media-media promosi seperti televisi, media cetak serta media sosial.

Kami mewawancarai beberapa nasabah hasanah card tentang 
pengetahuan mereka dalam keunggulan hasanah card di banding produk yang lain:

"Itu terutama murah karena adanya cash rebate tadi kalau kita bicara margin atau bunga .kalau di bank konvesional untuk ritele ya 3,5\%/bulan belum lagi administrasinya dan apa sebagainya jadi ini bisa sampai 5\%.kalau hasanah card itu tidak sampai $3 \%$ tapai $2,90 \%$ ini bisa terpotong dengan adanya dana cashrebate." (Muhammad Saleh)

"lebih mudah ya mba, murah juga,ada juga dewan syariahnya dan sesuai dengan syariat islam juga,selain itu saya suka cash rebate nya ,biasanya saya belanja kalau sudah ada promo mba "(Nur Wayu Octavia)

Nasabah cenderung memilih sebuah produk yang memiliki nilai lebih selain pada poin kehalalan (syariah), nasabah juga mempertimbangkan pada poin "transaksi tanpa riba" dan juga "transaksi dengan biaya murah", yang mana ini merupakan keunggulan dari produk hasanah card Bank BNI Syariah cabang makassar.

Nasabah menggunakan hasanah card karena salah satu faktor yaitu promo dan diskon-diskon yang terdapat di marchant-marchant. Sebagaiman wawancara kami dengan nasabah hasanah card:

"Diskon dari hasanah card ini, sejauh ini karena saya jarang menggunakan terus terang saya kurang begitu paham ada diskon atau tidak tapi memang sepengetahuan saya BNI Syariah memang kurang melakukan kerjasama dengan marchentmarchent tertentu atau tempat tempat tertentu dimana nasabah ketika menggunakan hasanah card transaksi di marchant tersebut itu ada diskonnya jadi memang masih kurang penawaran -penawaran diskon seperti itu tapi tidak mengurangi kenyamanan dan tingkat harga pricing yang dimiliki bank BNI Syariah masih tetap kompetitif sekalipun diskon tidak ada atau kurang "(Syam)

Berdasarkan wawancara diatas bahwa produk hasanah card yang ada di kota makassar memiliki diskon dan promo kurang hal ini mengakibatkan minat nasabah terhadap produk ini tidak mengalami peningkatan yang signifikan, akan tetapi tidak mengurangi kenyamanan dan tingkat harga pricing yang di miliki bank BNI Syariah masih tetap kompetitif sekalipun diskon ada atau kurang.

Minat nasabah terhadap produk hasanah card di Bank BNI Syariah, yaitu tentang alasan yang melatar belakangi mengapa memilih hasanah card dan mengapa memilih BNI Syariah. Sebagaimana wawancara kami salah satu nasabah yang mengunakan hasanah card:

"Saya memilih kartu kredit hasanah card. Yang pertama terlepas dari semua hal yang murah itu hasanah card kan 
sistemnya syariah juga jadi dia itu tidak perinsip bunga berbunga tidak sama dengan kartu kredit pada umumnya, hasanah card itu tidak berprinsip bunga berbunga dia itu cuman yang di pakek aja yang di kenakan margin adapun margin yang di kenakan itu akan kepotong dengan cash rabate jadi konsumen semakin merasa terbantu dengan adanya cash rebate itu tapi itu masuk di banevit terus kedua itu memang dia sangat murah karena dia syariah."(Muhammad Saleh)

Menurt penulis yang melatarbelakangi nasabah memilih hasanah card karena murah dan sesuai dengan syariah, di bandingkan dengan bank konvensional mengunakan sistem bunga berbunga hal ini akan merugikan nasabah.

Dalam menetukan minat nasabah terhadap produk bank sayriah yaitu penilaian masyarakat terhadapa layanan dan integritas pegawai bank syariah. Kami akan mewawancarai nasabah hasanah card mengenai kualitas pelayanan yang terdapat di bank BNI syariah,mewawancarai salah satu nasabah yang mengunakan hasanah card, dimana semua informan yang kami wawancarai menyatakan puas dengan fasilitas dan pelayanan bank BNI Syariah:

"Alhamdulillah puas yah mba, fasilitasnya dan pelayanannya juga disini" (Hasrullah)
Menurut observasi dan wawancara penulis selama penelitian di bank BNI Syariah terbukti pelayanan terhadap nasabah sangat baik dan tidak ada komplain nasabah terhadap fasilitas yang ada di bank BNI syariah. Pelayanan terhadap nasabah akan memepengaruhi minat nasabah dalam bekerja sama dengan bank BNI Syariah.

\section{KESIMPULAN}

Secara prinsip kartu kredit dalam Islam dibolehkan selama dalam praktiknya tidak bertransaksi dengan sistem riba yaitu memberlakukan ketentuan bunga bila pelunasan hutang kepada penjamin lewat jatuh tempo pembayaran. Sebagaimana sudah di tetapkan fatwa oleh DSN-MUI NO 54/DSN-MUI/X/2006.

Kontrak perjanjian hasanah card ada beberapa tahapan antara lain A/Ariyah (perjanjian kredit), Al-Wakalah (perjanjian pemberian kuasa), dan AlKafalah (perjanjian dengan penanggungan).

Persepsinasabah terhadap banking card syariah dilihat dari pengetahuan nasabah terhadap hasanah card sangat kurang. Diskon dan promo kurang hal ini mengakibatkan minat nasabah terhadap produk ini tidak mengalami 
peningkatan yang signifikan, akan kurang, kemudian untuk pelayanan tetapi tidak mengurangi kenyamanan terhadap nasabah sangat baik dan dan tingkat harga pricing yang di miliki tidak ada komplain nasabah terhadap bank BNI Syariah masih tetap fasilitas yang ada di bank BNI syariah. kompetitif sekalipun diskon ada atau

\section{DAFTAR PUSTAKA}

,Al-Qur'an dan terjemahnya.

Aladip, machfuddin. 1985. Bulughul Maram. Semarang: PT Karya Toha Putra.

Antonio, Syafi'i. 2011. Bank Syari'ah: Dari Teori Ke Praktek. Jakarta: Gema Insane.

Anwar, Syamsul. 2007. Hukum Perjanjian Syariah. Jakarta: PT Rajagrafindo Persada.

Ayub, Muhammad. 2007. Understanding Islamic Finance. Jhon Wiley \& Sons, Ltd.

Ascarya. 2008. Akad \& Produk Bank Syariah. Jakarta: PT Rajagrafindo Persada.

Ash Shiddieqy, Hasbi.Pengantar Hukum Islam (Jakarta,Bulan Bintang:1999,hal.63

Arifin, Muhammad. 2008. Sifat Perniagaan Nabi Saw. Bogor: Pustaka Darul Ilmi.

Al-Musyaiqih, Khalid Bin Ali. 2012. Buku Pintar Muamalah. Klaten: Wafa Pres.

Basyir, Ahmad Azhar, 2004. Asas-Asas Hukum Muamalat (Hukum Perdata Islam). Yogyakarta: Uii Press.

Chapra, M. Umer. 2000. Sistem Moneter Islam. Jakarta: Gema Insane Press.

Departemen Pendidikan Nasional. 2001. Kamus Besar Bahasa Indonesia. Jakarta: Balai Pustaka, Cetakan Pertama Edisi III:18.

Wibowo, Edi dan Untung Hendi Widodo. 2005. Mengapa Memilih Bank Syariah. Bogor: Ghalia Indonesia.

Ibrahim, Abdul Wahab. 2006. BANKING CARDS Syariah. Jakarta: PT Rajagrafindo Persada.

Karim, Adiwarman. 2008. Bank Islam: Analisis Fiqih Dan Keuangan. Jakarta: PT.Rajagrafindo Persada. . 2011. Ekonomi Maikro Islam. Jakarta: Rajawali Pres.

Mardani. 2012. Ayat Ayat dan Hadist Ekonomi Syariah. Jakarta: Rajawali Pers.

Moleong, Lexy J. 2007. Metodolgi Penelitian Kualitatif. Bandung: PT. Remaja Rosdakarya.

Rahim, Abdul.. 2013. Bank dan Lembaga Keuangan Syariah NonBank. Makassar: Gunadarma IImu.

Patrik, Purwahid. 1994. Dasar-Dasar Hukum Perikatan (Hukum yang lahir dari Perjanjian dan dari Undang-Undang. Cet. I; Bandung: Mandar Maju. 
Sugiyanto. 2008. Metodepenelitian Pendidikan. Bandung: CV. Alvabeta.

Sjahdeni, Sutan Remy. 2010. Perbankan Syariah. Jakarta: PT Jayakarta Agung Offset.

Syarifudin, Amir. 2003. Garis Garis Besar Fiqih. Bogor: Kencana, Renada Media. Undang Undang Perbankan Syariah. 2008. Jakarta: Sinar Grafika. 